\title{
The Teaching Design of English Reading Based on Cultivating Students' Critical Thinking
}

\author{
Yu Jia \\ Chongqing Normal University, China \\ Lei Guo \\ Chongqing Normal University, China
}

\begin{abstract}
The High School English Curriculum Standard (2017 edition) states that it's crucial to cultivate core competences for students, which includes language ability, learning ability, cultural awareness and thinking quality. There is no doubt that critical thinking, as one of the key components of thinking quality, should be emphasized. However, due to the influence of examination-oriented education and other factors, most teachers tend to pay too much attention to the cultivation of students' language knowledge and language skills, neglecting the cultivation of students' critical thinking ability. The traditional mode of interpretation of language knowledge still dominates in most English reading teaching, teaching design tends to be modeled and text processing is so superficial that students can not understand the discourse deeply. Students in the classroom did not experience a deep thinking level of ability training. Therefore, teachers should think carefully about how to cultivate students' critical thinking in high school English reading class and adjust their teaching methods accordingly. This paper will take the teaching design of a reading lesson as an example to explore how to cultivate students' critical thinking in high school reading class.
\end{abstract}

Index Terms - English reading, teaching design, critical thinking

\section{INTRODUCTION}

In recent years, scholars and teachers abroad and at home have paid much attention to the core competences of English discipline. The High School English Curriculum Standard (2017 edition) states that core competence consists of language ability, learning ability, cultural awareness and thinking quality. Critical thinking is the key component of thinking quality, cultivating the students' critical thinking meets the requirement of education curriculum. As an important part of human thinking, critical thinking plays an important role in the development of science and technology, economic growth, social development and human progress and has been identified as one of the standards for high school accreditation and a long-standing outcome of education. English reading enables students to acquire language knowledge and information, and it is also a good way to cultivate critical thinking. Critical thinking is needed as an important means to process information when reading. However, in most high school English reading classes, teachers only focus on a superficial understanding of the text and training of reading skills. There are quite a lot of problems in the teaching design. For example, students' original cognition has not been activated; teachers do not interpret the text deeply or accurately which makes it impossible for students to comprehend the text correctly; teaching steps' lack of coherence; the design of the question after reading is separated from the text and cannot be connected with the students' real life, which makes the teaching boring and tedious, students' critical thinking cannot be effectively trained. The design of questions and activities can serve as a support for the cultivation of critical thinking, allowing students to discover, analyze and solve problems. Taking the teaching design of reading text The Freshman Challenge, chosen from Unit1 Teenage Life, Compulsory one, PEP as an example, this paper explores how to cultivate students' critical thinking in reading teaching design.

\section{CRITICAL THINKING AND CRITICAL READING}

Critical thinking was first proposed by the American educator Dewey in 1909. So far, there is no unified definition. Liu Rude (2000) believes that critical thinking refers to the personal judgment of the authenticity, accuracy, nature and value of what is learned, so as to make reasonable decisions on what to do and what to believe. Halpern (2001) believes that critical thinking is the ability to analyze, synthesize, and evaluate information and the tendency to put these abilities into practice. Li Ruifang (2002) argues that the essence of critical thinking is a process of questioning, which gradually generates new views of the subject itself by asking different questions. Wen Qiufang (2006) believes that the cultivation of critical thinking should focus on the cultivation of the ability to think critically, the process of forecasting, evaluating, analyzing, refuting, and summarizing. Zhu Xincheng (2006) proposes that critical thinking is logic-oriented. It requires a rigorous approach to make reasonable and rational judgments about the people or things. This article argues that critical thinking requires students to use methods such as prediction, analysis, questioning, inference, summarization and judgment to recognize, understand, and process the information contained in the text, and then interpret, analyze 
and evaluate the text to achieve a deeper understanding of the text.

Critical thinking and critical reading are two closely related concepts. Reading is an important way to cultivate critical thinking, and critical thinking is the premise for critical reading. Phillip (2002) points out that critical reading not only requires readers to understand the basic information, but also interpret its implied meaning. Fan Li (2008) believes that critical reading is not a way for readers to browse the text roughly and passively accept and memorize the content within it, but a reading strategy that analyzes, integrates and analyzes the author's views, intentions, and assumptions. Chen Lingjun (2010) believes that the purpose of critical reading is to analyze and evaluate textual information on the basis of the understanding of the text so as to help people form their own views and attitudes. Based on the definitions of several researchers, critical reading can basically be divided into two levels. The first level is the interpretation of the text, which means to understand what the author wants to express. The second level is to evaluate the opinions and attitudes conveyed by the text and express the reader's own opinions and attitudes.

Flynn (1989) points out some skills in critical reading, such as previewing, predicting, questioning, analyzing, summarizing, annotating and evaluating. The teaching design should guide students to employ critical reading skills to help students reach a deep and comprehensive understanding of the text, and their critical thinking will be trained and developed in the process of long-term practice.

\section{An Example and Analysis of Teaching Design of English Reading for Cultivating Critical Thinking}

The author designed a reading lesson for Unit1: The Freshman Challenge which is selected from PEP.

Text analysis: The text is chosen from Unitl Teenage Life, compulsory one, PEP, with the title: The Freshman Challenge. The passage mainly talks about the challenges Adam faced when he had just entered high school in the first person. It's a narrative writing. There are 4 paragraphs in the text. The content of the text is constructed according to "Main point-Supporting ideas". The first paragraph is the main point, which explains the confusion that Adam had in his first week of high school. The remaining three paragraphs describe Adam's challenges in choosing courses, extra-curricular activities and study, as well as his feelings and strategies dealing with challenges.

Students analysis: My students are in Grade one in a senior high school in Chongqing. They are able to get basic information about Adam's challenges in the text, which will be helpful to carry forward the teaching procedure. But they are not able to express their own challenges independently and need the teacher to provide scaffolding as guidance. This is also their first week in class. Since this text is about freshman challenge, which is quite close to their present lives, they may have great interest in it.

Teaching objectives: After learning, students can 1) Be familiar with the words: freshman, challenge, recommend...2) Figure out what Adam's three challenges are, his feelings and the solutions he takes. 3) Figure out the structure of the text. 4) Talk about their own challenges now according to the scaffolding.5) Analyze Adam's qualities based on discourse and learn from him.6) Learn some cultural knowledge about America properly.(Chinese course in America).The Focal points in this lesson are points 2 and 3, and students may have difficulties in analyzing Adam's qualities based on discourse alone.

Teaching procedure: The teaching procedure consists of 5 parts as follows.

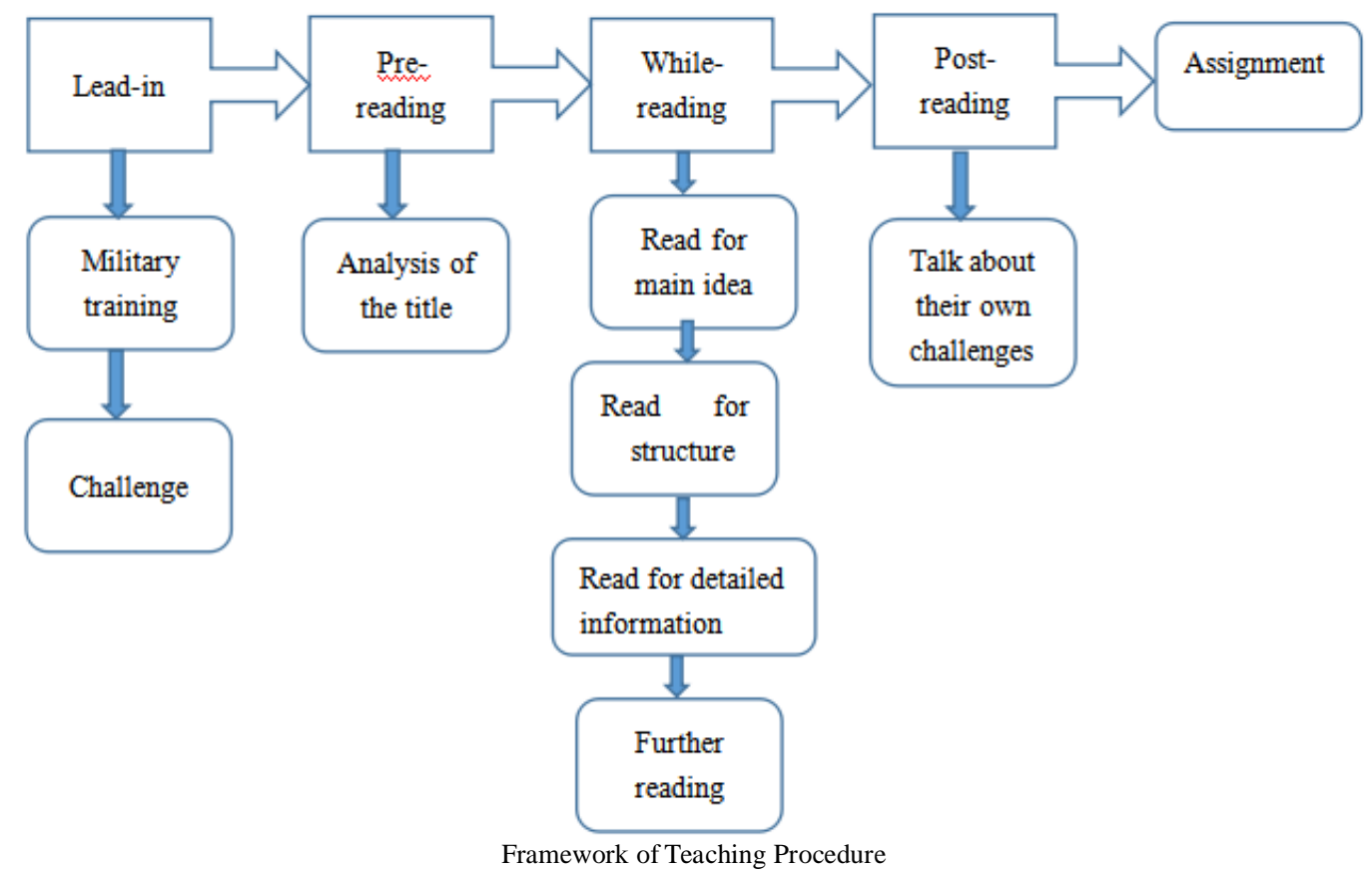




\section{Step1 Lead-in}

The teacher asks students the following questions.

\section{Q1: What were you doing last week?}

\section{Q2: How many days have you been in military training?}

Q3: Do you enjoy it? why?

T: Military training is the first challenge of your senior high school life.

[Explanation] For the students are new in senior high school, they have just finished their military training, it attracts their attention easily and they would be able to talk something about it. Q3 is designed to express their opinions. There is no doubt that some of students enjoy it while the others do not for the reason that it makes them too tired or exhausted, today's topic "challenge" can then be carried out smoothly.

Step 2 Pre-reading

Analysis of the title: "The Freshman challenge".

Q1: Paraphrase of the key word "challenge".

$$
\text { Something difficult: something that tests your strength, skill or ability especially in a way that is interesting. }
$$

Longman Dictionary Of Contemporary English

\section{Q2: Brainstorm \& Predict: What does "freshman" mean?}

[Explanation] Firstly, the teacher tries to use paraphrasing to explain the key word "challenge", although challenge is difficult, it tests our strength, skill or ability. It guides the students to view the challenge critically. The teacher then uses word-formation to brainstorm and predict the meaning of the word "freshman", it is a compound word, so students' predictions vary. The information gap stimulates students' interest to check their predictions by reading. In the pre-reading part, the teacher can also ask the students to predict what the passage will talk about according to the title. As freshmen in senior high school, they have obviously encountered many challenges. As such, they will think from multiple angles and dimensions. In the meantime, the teacher can also interpret the inner meaning of the core word "CHALLENGE" as follows, and then guide students to be confident, active and energetic when encountering challenges.

\begin{tabular}{|l|l|l|}
\hline C & Confident & You are sure to be the winner. \\
\hline H & Helpful & It's a good way to test your strength and ability. \\
\hline A & Active & Have an active attitude towards troubles. \\
\hline L & Logical & A logical mind helps to solve problems. \\
\hline L & Learned & Be learned in a specific field. \\
\hline E & Earnest & Take it seriously and try your best to do it. \\
\hline N & Nimble & A nimble mind creates more ideas. \\
\hline G & Gamy & Don't be afraid of the challenge. \\
\hline E & Energetic & Keep yourself full of energy to meet the challenge. \\
\hline
\end{tabular}

\section{Step 3 While-reading}

\section{Activity 1: Read for main idea}

After skimming, Teacher asks students the following questions.

\section{Q1: Who is the writer of the passage?}

Adam.

\section{Q2:How about Adam's identity? How do you know it?}

New student. Because this is Adam's first week in senior high school.

\section{Q3:How was Adam's first week in senior high school?}

The first week was a little confusing.

\section{Q4: Why did Adam feel confused?}

Because senior high school is a challenge.

Q5: Why does Adam think his senior high school life is a challenge?

(Tip: topic sentence: usually the first sentence of each paragraph)

[Explanation] Five questions in Activityl are logically related, aiming to train students' reading skill by skimming for information. Question 1, 2,3 and 4 are based on paragraph one. Q5 is to help them check the topic sentence they underline, which helps students to understand the main idea and the structure better. After answering the above five questions, the students will understand the main idea clearly.

Activity 2: Read for structure.

Ask students the following questions.

\section{Q1: What challenges did Adam meet? (topic sentences)}

\begin{tabular}{|l|l|}
\hline Para1 & Senior high school is a challenge. \\
\hline Para2 & First, he had to think very carefully about which courses he wanted to take. \\
\hline Para3 & Adam had to choose extra-curricular activities, too. \\
\hline Para4 & Adam will have to study harder in the future and get used to being... \\
\hline
\end{tabular}


Q2:How do you understand the conjunction "first", "too" in the topic sentence of para2 and para 3? Q3:How to divide the passage? why?

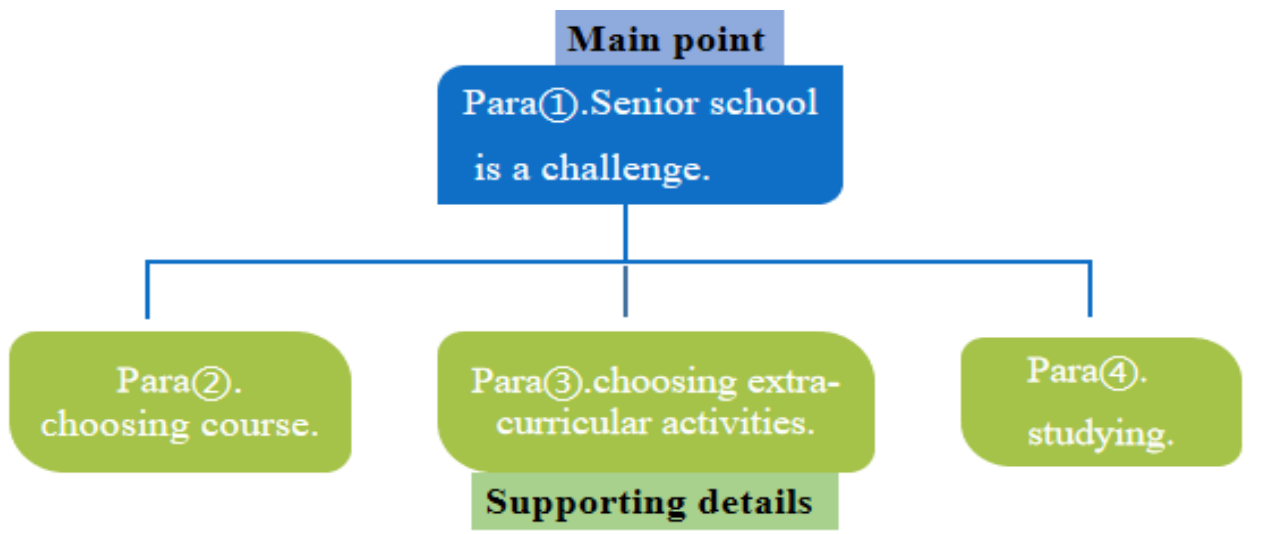

[Explanation] Finding the main line of text helps to restore the author's writing ideas. Under the guidance of the main line of text, the reader can easily understand the transition between the various paragraphs and the correlation between the information points. In this part, the teacher uses three questions to provide a scaffold for students' thinking to clarify the relationship between paragraphs. Q1 is to let the students develop awareness of the structure "Main point-Supporting ideas". Q2 is to make students aware of the parallel relationship of "supporting ideas" through the conjunctions of "first" and "too", so that students can clearly understand the structure of the text. Critical thinking is not developed independently. There should be close connections between the various steps in the teaching design, which constitute the supporting point for the development of critical thinking.

Activity 3: Read for detailed information

Read the text again to finish True or False question.

( F )1. Adam didn't choose Chinese as his suitable course because it's too hard.

[Original sentence 1] I know that Chinese is a very difficult language, but I hope to be fluent when I graduate.

( F )2. Adam joined the football team instead of a volunteer club.

[Original sentence 2] I tried to join the school football team, but the coach told me that I didn't play well enough. I joined a volunteer club instead.

( T )3. Adam is worried about keeping up with the other students and getting used to all the homework.

[Original sentence 3] I'm a bit worried about keeping up with the other students in my advanced course and it'll be quite difficult to get used to all the homework.

( F )4. Adam doesn't feel happy because of his worries.

[Original sentence 4] Still, I'm happy to be here.

[Explanation] Four detailed questions based on paragraph 2 - 4 to train students' scanning ability, students will understand the passage better by finding out the supporting ideas. And these questions are also helpful to complete the following outline.

Complete the outline in Task 4 on page 15.

\begin{tabular}{|c|l|l|l|}
\hline Paragraph & Challenge & Feelings & Solution \\
\hline 1 & & confused & The school adviser... \\
\hline 2 & Choosing courses & & \\
\hline 3 & & & \\
\hline 4 & & & \\
\hline
\end{tabular}

[Explanation] This table is to help students classify and generalize Adam's challenges, feelings, and solutions and exercise students' ability to extract key information by scanning. It stimulates students' language input through different forms of tasks that are easier to understand, such as pictures and tables.

\section{Activity 4: Further reading}

Q1: Why did Adam choose Chinese which is a very difficult language as his suitable course? (T: show the students the following cultural note while inferring.)

Cultural Note
In North America, many schools allow students to choose courses they want to take. Chinese is increasingly being taught as a
foreign language in Western high schools. However, in north America by far, the most popular foreign language taught in high
schools are French and Spanish.

Q2: What kind of person do you think Adam is? Why? 


\begin{tabular}{|c|c|}
\hline Qualities & Supporting sentences \\
\hline Determined & I was unhappy, but I won't quit. \\
\hline Warmhearted & He joined a volunteer club. \\
\hline Positive & Still, I am happy to be here. \\
\hline Confident & I like English and I am good at it. \\
\hline$\ldots$ & \\
\hline
\end{tabular}

[Explanation] To develop students' critical thinking, teachers need to first understand the text deeply. Authors often do not express details too bluntly, but omit relevant information that the reader may know or can infer. The process of reading is just the opposite. Readers need to use their existing knowledge to reconstruct the text content in order to explore the deep meaning of the text. Q1 is to guide the students to think deeply. The answer to the question cannot be found from the text directly, the students need to combine the text with common sense to make inferences, which belongs to the deep-level question of exploring the hidden information of the text. Although Chinese is quite difficult to learn, Adam still chooses it as his suitable course, because Chinese is increasingly being taught as a foreign language in Western high schools, which implies Chinese nowadays is becoming more and more international. Q3 is to analyze the Adam's qualities based on discourse, students need to infer and summarize according to the discourse by themselves.

\section{Step 4 Post reading}

Talk about one of your challenges with your partners, and then try to use the following scaffolding to make an oral report.

Q1: What challenges are you facing now?

Q2: How do you feel?

Q3: How do you deal with them?

As a freshman in senior high school, I have difficulty in .... now. (challenge). I feel... (feeling) But when we are faced with challenges, we should learn from Adam. The sentence “...”"shows that he is ...(quality) My friends/parents recommend that I should...So I will find a way to...(solution)

[Explanation] In this part, students will think carefully about their own challenges now after figuring out Adam's challenges. The oral report design based on students' daily lives is more conducive to students' active participation in the classroom, it helps to awaken students' subjective consciousness, develop their intelligence and give full play to their initiative. Students are not only required to synthesize the relevant information and language in the text, but also combine their original language knowledge and cognition and express their own views. At this time, students need to use higher-order thinking. In this way, students' thinking ability will be further improved. The pattern is provided by the teacher, most expressions and key words are selected from the text such as "recommend that somebody should do something, find a way to...", and almost all the key elements in this passage are included. On the other hand, it provides a scaffolding for the students, it also guides them to learn from Adam. In the teaching of English writing, the reading process is an important input link, and the activities after reading is a vital for evaluating the level of reading comprehension and language ability.

Step5 Assignment

Requirement: Write a short passage about your challenges now.

Optional: Think about the following questions.

1.What are some differences between Adam's school life and your school life?

2. What does the name "Adam" mean in western culture?

[Explanation] The writing helps the students consolidate some important words and expressions of the text. In addition to improving the students' thinking ability in the classroom, teachers can also provide students with enough opportunities to develop their critical thinking after class, so that students' critical thinking can be extended wider and deeper. The teacher asks students to compare their school life and Adam's school life to realize the similarities and differences between Chinese and Western cultures. In this way, their critical thinking ability will be trained effectively. The author's name "Adam" also has its implied meaning. Adam is the first man created by God in Abrahamic religions, in the passage Adam is a freshman in senior high school, it has a symbolic meaning of "new". In addition, some thought-provoking questions can be put forward for students to think about. For example, the teacher can also ask students to think about the pros and cons of the challenge, which is based on the content of text but goes beyond text. It would be quite an effective way to train students' critical thinking.

\section{CONCLUSION}

The teaching design firstly uses military training that is close to the actual life of the students to stimulate their enthusiasm and interest in reading. In pre-reading, the author's teaching plan is to tackle two core words "challenge" and "freshman", which helps to clear some obstacles for reading. As has been mentioned before, teachers can also guide students to predict the main content according to the title and illustrations, or brainstorm some background information in this part, because in this way their prior knowledge can be utilized. The reading part consists of four parts: Read for main idea, structure, detailed reading and further reading. The activities and questions for each part are designed hierarchically. Firstly, teachers guide students to grasp the main idea and structure of the article, then lead students to 
further understand the detailed language points, such as new words, phrases and interpretation of difficult sentences. This process can develop students' ability to interpret, analyze, reason and explain. After that, students can be guided to pay attention to the author's writing intention or attitude, and the method of author's argument. At this time, teachers need to allow students to refine, summarize, and compare the viewpoints in the text, and analyze the logic, rationality and coherence of the argument. In post reading, on the basis of consolidating what they have learned, the teacher tries to give students the opportunity to fully express themselves. Teachers can give students different oral or written tasks, for example, they can make comments on the topic of the article, or give a similar topic and let students imitate the structure to write. In this way, students' critical thinking can be clearly reflected. For assignment, teachers can leave some thought-provoking questions for students to think about after class, which is quite helpful for their development of thinking.

Cultivating students' thinking ability is to cultivate students' ability to understand the text on a deep level, the design of teaching activities cannot be limited to the query and understanding of the basic information of the text. Therefore, teachers must strive to elucidate the connotation of the teaching materials. The questions designed for teaching activities should be logical and based on a deep and accurate interpretation of the text. It is worth mentioning that the questions designed for students should be in accordance with their cognitive levels. When designing questions, teachers should take the students' current cognitive level and their potential development level into consideration and what's more, various questions in the previous three stages should be distributed in a proper way, only in this way can their learning potential be stimulated effectively.

\section{REFERENCES}

[1] Ennis, Robert H, A. (1985). Logical basis for measuring critical thinking skill. Educational Leadership, 2, 44-48.

[2] Fan Li. (2008). New thinking of foreign language reading-Critical reading mode. English Studies,4, 81-85.

[3] Flynn, L.L. (1989). Developing critical reading skills through cooperative problem solving. Reading Teacher, 6, 664-668.

[4] Golding, C. (2011).Educating for critical thinking: Thought-encouraging questions in a community of inquiry. Higher Education Research and Development, 30, 357-370.

[5] Halpern, D. F. (2001). Assessing the effectiveness of critical thinking instruction. The Journal of General Education, 23, 270-286.

[6] Liu Rude. (2000). The significance and connotation of critical thinking. Research on Higher Normal Education, 12 , 56-610.

[7] Li Ruifang. (2002) Foreign language teaching and cultivation of students' creative and critical thinking. Foreign Language Teaching, 5, 61-65.

[8] Paul R \& Elder L. (2005). Critical thinking: learn the tools the best thinkers use. New Jersey: Pearson Prentice Hall.

[9] Pirozzi, Richard \& Starks, Martin \& Julie, Dziewisz. (2008). Critical reading, critical thinking. New York: Addison-Wesley Educational Publishers Inc.

[10] Peter A. Facione. (2013). Critical thinking: What it is and why it counts. Millbrae, CA: Measured Reasons and California Academic Press.

[11] Ruth, M, Jo. Lally. (2010). Thinking teacher's toolkit: Critical thinking, thinking skills and global perspectives. New York: Continuum International Publishing Group.

[12] Wen Qiufang \& Zhou Yan. (2006). Comments on the development of thinking ability of foreign language majors. Foreign Language Research, 5, 76-80.

[13] Zuhana Mold Zin. (2014). Critical reading ability and its relation to L2 proficiency of Malaysian ESL learners. English Language Studies, 20, 43-54.

[14] Zhu Xincheng.(2006). Cultivation of critical thinking for college students: significance and strategy. Journal of the South China Normal University, 3, 123-126.

Yu Jia was born in Zhejiang, China in 1996. He is currently pursuing his M.Ed degree in Chongqing Normal University, Chongqing, China. His research is mainly focused on EFL teaching. He has been working as a part-time job teacher in Education Institution for 6 years.

Lei Guo was born in Sichuan, China in 1995. Now, he is a postgraduate student in Chongqing Normal University, China. His research interests include foreign language teaching and cognitive linguistics. 